\title{
A SANÇÃO PEDAGÓGICA E OS ASPECTOS \\ ÉTICOS E MORAIS DA CONSENSUALIDADE: \\ EM BUSCA DA EFETIVIDADE DO MODELO MULTIPORTAS ${ }^{1}$
}

\section{PEDAGOGICAL SANCTION AND THE ETHICAL AND MORAL ASPECTS OF CONSENSUAL MODEL: \\ SEARCHING FOR MULTI-DOOR SYSTEM EFFECTIVENESS}

Márcia Michele Garcia Duarte

Pós-Doutora em Democracia e Direitos Humanos pela Universidade de Coimbra/Portugal (2015-2016). Pós-Doutora em Direito Processual pela UERJ (2013-2015). Doutora em Direito (2009-2012), Mestra em Direito (2006-2007) e Especialista em Direito e Didática do Ensino Superior (20032004) pela UNESA/RJ. Professora Adjunta de Direito Processual da Universidade Federal Fluminense (UFF), da Universidade do Estado do Rio de Janeiro (Graduação e Programa de Pós-Graduação em Direito - Mestrado e Doutorado) e da Universidade Estácio de Sá (UNESA). Parecerista ad hoc da Revista Eletrônica de Direito Processual da UERJ (REDP), da Revista CEJ (Conselho da Justiça Federal/Centro de Estudos Judiciários) e da Revista Eletrônica do Conselho Nacional de Justiça (CNJ). Chefe de Departamento na UFF no biênio 2016-2018. Coordenadorageral do Núcleo da Prática Jurídica da UERJ. Coordenadora de Banca no Exame Nacional da Ordem dos Advogados do Brasil. Membro do Instituto Brasileiro de Direito Processual (IBDP) e do Instituto Carioca de Processo Civil (ICPC). Rio de Janeiro/RJ. E-mail: marciaduarte.juridico@gmail.com

\footnotetext{
${ }^{1}$ Artigo recebido em 17/04/2021 e aprovado em 04/06/2021.
} 
RESUMO: O presente ensaio busca provocar o enfrentamento do aspecto comportamental nos espaços de desenvolvimento da Alternative Dispute Resolution (ADR), notadamente na negociação extraprocessual. Perpassa pelos deveres que norteiam todos que utilizam a vestimenta do "atuar colaborativo", convidando à reflexão acerca da viabilidade de construir comportamentos despidos de artifícios, ou dos subjetivismos e elementos subjacentes que marcam a busca por razões e vitórias, no sentido de conduzir a resultados irascíveis aos demais participantes do espaço até então rotulado como consensualizado. A pesquisa classifica-se como bibliográfica e descritiva, pois se pauta em doutrina interdisciplinar e busca conferir nova visão sobre o assunto. Pensa-se que a punição pecuniária se mostra promissora a amoldar os conflitantes, no fito de levá-los efetivamente a submergirem, sem meio-termo, no oceano de possibilidades reais de resolução amigável (e confiável) dos conflitos.

PALAVRAS-CHAVE: ADR; cooperação processual; negociação ética; boa-fé processual; moralidade colaborativa.

ABSTRACT: The present essay endeavors to spark behavioral aspects in Alternative Dispute Resolution (ADR) development spaces confrontation, remarkably in extraprocedural negotiation. The issue runs through duties that direct everyone who wears the "collaborative acting" clothing, inviting to reflection on the possibility of building behaviors devoid of artifice or subjectivisms, and subjacent elements that mark the search for reasons and victories, in order to lead irascible results to other room participants thus far labeled as consensual. Note well this is a bibliographic and descriptive research given that it is based on interdisciplinary doctrine proposing a new perspective on the subject matter. Financial punishment is thought to be promising for shaping conflicting people, so as to effectively guide them to submerge, with the appropriate compromise, in the ocean of real possibilities for friendly (and reliable) resolution of conflicts.

KEYWORDS: ADR; procedural justice and cooperation; negotiation ethics; procedural good faith principle; collaborative morality ${ }^{2}$.

\footnotetext{
${ }^{2}$ Tradução realizada por Clarissa Xavier Machado.
} 


\section{Considerações iniciais}

Se queremos edificar um novo aparelho judicial, isento das chagas que enfeiam a face da Justiça, é mister antes de mais nada que nos libertemos de falsas ideias (MOREIRA, 2004).

Partindo da frase conclusiva do magistral José Carlos Barbosa Moreira ${ }^{3}$ no seu assentamento (ou aconselhamento) acerca da construção dos mitos ao futuro da justiça, vemo-nos num cenário onde se deflagram as reflexões acerca dos assuntos que aqui serão explorados, considerando o recorte do tema na nova sistemática tão aclamada, que resulta na construção ainda incipiente de um novo modelo de realização da justiça.

A referência é feita ao denominado modelo multiportas ${ }^{4}$ que, no sistema brasileiro, comporta essencialmente a arbitragem, a mediação, a conciliação e as negociações diretas, as últimas especialmente difundidas em períodos mais recentes por meio de plataformas digitais, a exemplo do modelo "consumidor.gov.br"5. São realizações que conquistam mais espaço nas formações acadêmicas ${ }^{6}$ e nos cursos de atualização de profissionais, além do

\footnotetext{
${ }^{3}$ MOREIRA, José Carlos Barbosa. Temas de Direito Processual. Oitava Série. São Paulo: Saraiva, 2004, p. 12.

4 “A expressão multiportas decorre de uma metáfora: seria como se houvesse, no átrio do fórum, várias portas; a depender do problema apresentado, as partes seriam encaminhadas para a porta da mediação, ou da conciliação, ou da arbitragem, ou da própria justiça estatal”. CUNHA, Leonardo Carneiro da. Justiça multiportas: mediação, conciliação e arbitragem no Brasil. Revista ANNEP de Direito Processual, Salvador/BA, v. 1, n. 1, art. 33, 2020, p. 140-162. Disponível em: https://revistaannep.com.br/index.php/radp/article/view/33/pdf. Acesso em: 2 mar. 2021.

${ }^{5}$ Serviço público disponibilizado pela internet para viabilizar a interlocução direta entre consumidores e empresas, possibilitando a solução de conflitos de consumo. O Ministério da Justiça, por meio da Secretaria Nacional do Consumidor (Senacon), monitora a ferramenta com auxílio dos Procons, das Defensorias, dos Ministérios Públicos e de toda a sociedade. Disponível em: https://www.consumidor.gov.br/pages/conteudo/sobre-servico. Acesso em: 13 abr. 2021.

${ }^{6}$ Assinala-se a Resolução n ${ }^{\circ}$ 5, de 17 de dezembro de 2018 que "Institui as Diretrizes Curriculares Nacionais do Curso de Graduação em Direito e dá outras providências." Nesse sentido, em nosso estudo anterior apresentamos que "significativamente, aponta-se mais um avanço acerca da temática de mediação: seu estudo passará a ser conteúdo de disciplina obrigatória nas Instituições de Ensino Superior (IES), conforme determinação estabelecida nas Diretrizes Curriculares Nacionais (DCN) do curso de graduação em Direito. Exige-se, a partir desse instrumento normativo e respeitado o prazo de implementação, que 'formas consensuais de solução de conflitos' componham o quadro de disciplinas a serem necessariamente ofertadas nos cursos de Direito (disciplinas obrigatórias). Até então ausente de regulamentação impositiva, a matéria poderia ser oferecida como palestras, disciplina eletiva/optativa ou mesmo sequer disponibilizada no curso de Direito de algumas faculdades". DUARTE, Márcia Michele Garcia Duarte. O papel social do advogado no primado da mediação e a argumentação participativa. In: PINTO, Adriano Moura da Fonseca Humberto; PINHO, Dalla Bernardina; DUARTE, Márcia Michele Garcia; MARTÍN, Nuria Belloso (Coord.). Estudos sobre mediação: no Brasil e no exterior. Essere nel Mondo, Santa Cruz do Sul, v. 1, p. 194-211, 2020.
} 
costumeiro aprofundamento nas instituições acadêmico-científicas. Nessas instituições, os novos estudantes encantam-se com a proposta de realização da justiça de maneira harmoniosa e idealizada. Já no âmbito da prática jurídica, digladiam-se profissionais de vanguarda e retrógrados quanto à utilidade e produtividade da audiência de conciliação e da sessão de mediação. Ainda com feições de advocacia colaborativa, a matriz adversarial, que formou gerações e influenciou o pensar o direito a partir da ótica da melhor estratégia processual para aniquilar o oponente, luta internamente com quem se proponha a encontrar soluções denominadas "ganha-ganha", abdicando verdadeiramente das chances de receber o troféu egoico que poderia advir pela via judicial e revelaria o êxito integralmente processual.

Nessa esteira, veem-se, no aspecto prático da atuação nos campos do direito, flâmulas de paz e consensualidade algumas vezes intoxicadas por postura despótica, traições negociais e postergação intencional, com o fito de gerar enfraquecimento e descrédito, que podem levar a ganhos erigidos sobre a matriz da articulação e manipulação alheia. Esse tipo de comportamento por parte dos atores sociais, embora repugnante a olhos alheios, pode ser realizado e praticado irrefletidamente por todos que se encontram em conflito social, mesmo quando ainda despido da agravante que caracteriza a disputa em si.

Para atender a esse propósito, optou-se pela metodologia de pesquisa bibliográfica e descritiva, enfrentando o tema sob a ótica doutrinária interdisciplinar e apresentando nova abordagem sobre o assunto. Por este motivo, propõe-se, por meio do presente ensaio, articular fundamentos jurídicos e comportamentais como forma de chamar atenção para questão de tamanha importância prática, na expectativa de contribuir para a depuração do tema promissor e eficaz como é a solução verdadeiramente consensual dos conflitos.

\section{A ética nas negociações}

As negociações tomam parte considerável da vida de todos os indivíduos. Desde tenra idade, os humanos negociam nos aspectos mais simples, como o empréstimo de um brinquedo ao coleguinha, até aqueles relativos à rotina de cada lar, que dizem respeito a horários de alimentação e higiene, à utilização de equipamentos eletrônicos, especialmente

Disponível em: https://www.esserenelmondo.com/pt/direito-estudos-sobre-mediacao-no-brasil-e-no-exteriorebook193.php. Acesso em 14 abr. 2021. 
para o lazer, e à hora de dormir. Na vida adulta, ainda permanecem os jogos negociais entre os coabitantes de cada lar e com a comunidade externa, incluindo as esferas do trabalho, do lazer, no trânsito etc., incorporando todos os aspectos da vida. Até mesmo nas comunidades de animais ${ }^{7}$ é possível observar comportamentos de barganha por território e alimento.

Qualquer que seja o aspecto negocial, alguns elementos subjacentes perpassarão aquele momento e não tem como dissociar autonomamente a postura do negociador daquilo que consagra sua matriz enquanto essência, verdades e experiência vivenciada. No aspecto das resoluções consensuais, isso foi plenamente identificado e traduzido na obra de William Ury, Roger Fisher e Bruce Patton ${ }^{8}$, levando à estruturação de ferramentas para melhorar o resultado da mediação em sua motivação principal de atingir a (re)comunicação das partes em conflito. Atitudes como separar pessoas do problema, concentrar nos interesses e não nas posições, insistir em critérios objetivos e buscar alternativas de ganho mútuo são instruções claras e se mostram deveras eficazes na mesa negocial conduzida por mediadores.

Além disso, as negociações são permeadas por três variáveis básicas, como assinala Rubem José Boff ${ }^{9}$, classificando-as como poder $^{10}$, tempo ${ }^{11}$ e informação ${ }^{12}$ e geram a construção de um processo de negociação adequada. Aponta o professor que quatro são os princípios básicos para um bom negociador: 1. planejamento - consiste em antever todas as possibilidades que serão levantadas durante a discussão do acordo, incluindo preparação da base documental e mesmo buscar ouvir pessoas próximas ao interlocutor; 2. argumentação sólida - mesmo que seja necessário colocar no papel com o objetivo de definir a linha de raciocínio; 3. conhecimento do adversário - quando são ouvidos os

\footnotetext{
${ }^{7}$ É sempre oportuno difundir que o direito contemporâneo considera os animais de companhia como seres senciente, dotados de sensibilidade e com necessidades biopsicológicas, devendo a organização dos sistemas sociais considerar seu bem-estar.

${ }^{8}$ Trata-se da clássica obra URY, William; FISHER, Roger; PATTON, Bruce. Como chegar ao sim: como negociar acordos sem fazer concessões. Tradução: Rachel Agavino. Rio de Janeiro: Sextante, 2018.

${ }^{9}$ BOFF, Rubem José. Negociação: técnicas para a obtenção de resultados. Interlink, Aparecida de Goiânia, v. 2, n. 2, jul./dez. 2011. Disponível em: https://www.fd.unl.pt/docentes_docs/ma/tgau_MA_26100.pdf. Acesso em: 29 mar. 2021.

10 "O poder compreende: poderes pessoais e poderes circunstanciais. [...]. O poder pessoal compreende poderes, tais como: da moralidade, da atitude, da persistência, da capacidade persuasiva, da aparência, da vontade e da motivação". Idem.

11 “[...] para uma negociação ser bem sucedida, deve-se respeitar o prazo limite, embora, nem sempre termine quando um acordo é celebrado. Existe a fase de pós-negociação inserida no processo e, assim, deve-se administrar o tempo decorrido até à conclusão final das cláusulas negociadas”. Ibidem.

12 "Para que seja eficaz, a informação deve ser dada na linguagem do receptor, facilitando o entendimento. A utilização de recursos que impactem nos canais sensoriais visual, auditivo e sinestésico propicia resultados interessantes". Ibidem.
} 
amigos do interlocutor e os inimigos também, com o propósito de reunir o maior número de informações a seu respeito, buscando antecipadamente entender a forma como pensa e age em diferentes situações; 4. transparência - o elemento que inspira confiança em contraponto com o blefe, que o autor classifica como "um dos piores artifícios que um negociador pode usar. Descoberto, o engano acaba com toda a confiança existente entre as partes, e terminada a confiança, acaba a negociação" ${ }^{13}$ (grifos desse ensaio).

Sobre esse princípio da transparência, erige-se o mais salutar deste ensaio: a confiança nas negociações em sistemas autocompositivos de solução de conflitos. Entretanto, antes dessa abordagem, e ainda na esteira do embasamento perpassando no ambiente corporativo e sua projeção negocial, alguns outros componentes se destacam como pré-requisitos para a boa negociação: a comunicação interpessoal, consubstanciada na valorização da empatia e na busca da transmissão adequada da mensagem, antedatando-se para os sinais verbais e não verbais recebidos que revelam possibilidade de anuência e disponibilidade de ceder nos seus interesses; a flexibilidade, retratando o perfil de todo acordo ser dotado de certa margem inicial para negociar e viabilizar espaço hábil a concessões; a justiça, que significa atentar para uma das partes não ser prejudicada ou injustiçada, sobrelevando o resultado positivo obtido através do modelo ganha-ganha, reservando a sensação em todos os envolvidos de vitória relativa; o respeito, que pressupõe o dever postural cortês durante o processo de negociação, observando-se mais que a adequada atitude profissional e civilizada, mas também salvaguardando o respeito humano com os envolvidos. Por fim, a prudência, cuja expressão associa-se ao dever de cautela na realização do acordo, afastando comportamentos que fragilizem qualquer dos lados (grifos desse ensaio).

Essa miscelânea de comportamentos esperados derivada muitas vezes de contratos não ditos e encaminham para a observação de outro elemento salutar: a ética ${ }^{14}$. É notório se definir sempre essa expressão com o viés de comportamento humano em sociedade na esteira qualitativa do bem e do mal, de dever e de não dever, de modelos básicos ideais que sirvam

\footnotetext{
${ }^{13}$ Ibidem.

${ }^{14}$ Leonardo Boff descreve: "A ética é parte da filosofia. Considera concepções de fundo acerca da vida, do universo, do ser humano e de seu destino, estatui princípios de valores que orientam pessoas e sociedades. Uma pessoa é ética quando se orienta por princípios e convicções. Dizemos, então, que tem caráter e boa índole". BOFF, Leonardo. Ética e moral: a busca dos fundamentos. 2. ed. Petrópolis, RJ: Vozes, 2004, p. 37 sublinhado no original.
} 
para todos, respeitando a igualdade, interesse e direitos universalmente $\operatorname{considerados}^{15}$ (grifo desse ensaio).

Noutra monta, verifica-se haver ruídos importantes na comunicação humana daqueles que se envolvem notadamente em conflitos. Adverte Leonardo Boff acerca da grave crise mundial de valores, dificultando que a grande maioria da humanidade saiba o que é correto e o que não é. Sinaliza, quanto à ocorrência de "obscurecimento do horizonte ético", que gera "insegurança muito grande na vida e numa permanente tensão nas relações sociais que tendem a se organizar ao redor de interesses particulares do que ao redor do direito e da justiça". Nesse compasso, assegura o agravamento do fato em razão da construção competitiva que resulta da lógica dominante na economia e no mercado, dimanando em oposições e exclusões, e desviando-se da cooperação hábil a harmonizar e a incluir; termina por onerar o que seria o "encontro de estrelas-guia e de pontos de referência comuns, importantes para as condutas pessoais e sociais" ${ }^{\prime 16}$ (grifos desse ensaio).

Dito isso, sinaliza-se a importância do comportamento ético nas negociações, bem como sua fundamentalidade na pacificação dos conflitos humanos, devendo ser, portanto, estimulada desde a tenra idade, até nos espaços de grandes oportunidades negociais da humanidade.

\section{A cooperação "transprocesso"}

Quando se trata de cooperação processual, dissemo-la como comportamento entre autoridades judiciais (cooperação internacional e nacional), entre entes judicantes e não judicantes, e ainda entre o Poder Judiciário e o Juízo Arbitral. Quanto ao último, isso ocorre por meio do processo que Humberto Dalla Bernardina de Pinho e Marcelo Leite da Silva Mazzola denominam de "interface", justificando que as decisões arbitrais, por não serem dotadas de coercitividade, rogam a colaboração do Poder Judiciário em atuação executória. Essa provocação dá-se através da Carta Arbitral, prevista no inciso VI do art. 237 do CPC, e considera os doutrinadores que "disso decorrem alguns deveres para o árbitro e para o juiz,

\footnotetext{
${ }^{15}$ Nesse contexto, convém ressaltar o pensamento kantiano: "O imperativo categórico seria o que nos representasse uma ação como objetivamente necessária por si mesma, sem relação com nenhum outro fim". KANT, Immanuel. Fundamentação da Metafísica dos Costumes e Outros Escritos. São Paulo: Martin Claret, 2005 , p. 45.

${ }^{16}$ BOFF, Leonardo. Ética e moral: a busca dos fundamentos. Op. cit., p. 27.
} 
que devem atuar com eficiência e comprometimento nessa interface entre o Poder Judiciário e o Juízo Arbitral"17.

Também na interface da cooperação, veicula-se a função social como sendo algo almejado como provedor de resultados positivos e promissores, fundando-se na busca por caminhos possíveis ou caminhos exploráveis no sentido positivo, sempre com vistas à construção de espaços de fraternidade e de paz. Nesse compasso, cai bem citar novamente Leonardo Boff que leciona ser o bem comum, no plano humanístico:

o reconhecimento, o respeito e a convivência pacífica. Pelo fato de ter sido desmantelado sob a virulência da globalização competitiva, o bem comum deve agora ser reconstruído. Para isso, importa dar hegemonia à cooperação e não à competição. Sem essa mudança, dificilmente se manterá a comunidade humana unida e com um futuro que valha a pena ${ }^{18}$ (grifos desse ensaio).

Sob o viés processual, o bem comum proposto associa-se à cooperação e consagra o princípio orientador do processo civil positivado no art. $6^{\circ}$ do CPC/2015. Para Marcelo Mazzola, esse princípio encontra raízes entrelaçadas aos princípios e garantias fundamentais, consagrando o contraditório, a participação, a fraternidade, a solidariedade, a dignidade da pessoa humana, entre outros, concatenando que "em termos caricaturais, podemos dizer que a cooperação é um caudaloso afluente que deságua num grande rio constitucional" ${ }^{19}$. Quando busca o fundamento etimológico, o autor explica que o verbo latino cooperari tem influência na ideia de laborar em conjunto e obrando para determinado fim. No aspecto processual, o modelo cooperativo de processo pressupõe a "divisão de tarefas, redistribuição de responsabilidades e um pacto de trabalho, em que todos aqueles participam do processo" em prol da composição do litígio de forma justa, célere e eficaz, no que denomina de "gestão compartilhada do processo". ${ }^{20}$

\footnotetext{
${ }^{17}$ PINHO, Humberto Dalla Bernardina de. A cooperação como elemento estruturante da interface entre o Poder Judiciário e o Juízo Arbitral. Revista Eletrônica de Direito Processual (REDP). Rio de Janeiro, ano 11, v. 18, n. 3, p. 198-218, set./dez. 2017.

${ }^{18}$ BOFF, Leonardo. Ética e moral: a busca dos fundamentos. Op. Cit., p. 65

${ }^{19}$ MAZZOLA, Marcelo Leite da Silva. Tutela jurisdicional colaborativa: a cooperação como fundamento autônomo de impugnação. Curitiba: CRV, 2017, p. 81-82.

20 "incluindo o juiz, as partes, os advogados, a Defensoria Pública, o Ministério Público, entre outros" (Idem, p. 47).
} 
Sob o magistério de Daniel Mitidiero"21, a colaboração representa "modelo que se estrutura a partir de pressupostos culturais", compreendendo os ângulos social ${ }^{22}$, lógico $^{23} \mathrm{e}$ ético ${ }^{24}$, enquanto esse último ângulo refere-se ao processo pautado pela colaboração e confere relevo à boa-fé subjetiva e objetiva, tanto dos participantes quanto do judicante. Por boa-fé objetiva narra o autor o comportamento "merecedor de fé, que não frustre a confiança do outro", rechaçando abuso do direito e, como menciona claramente, a frustração à confiança. Ao tomar por empréstimo os conceitos materiais civilistas, o doutrinador enumera a exceptio doli ${ }^{25}$, o venire contra factum proprium $^{26}$, a inalegabilidade de vícios formais ${ }^{27}$, a supressio $^{28}$ e a surrectio ${ }^{29}$, o tu-quoque ${ }^{30}$.

Num olhar de aplicação antecipada ao processo em si (enquanto instrumento da jurisdição), coadunamos nossa reflexão com a exposição de Eric Navarro Wolkart ${ }^{31}$, quando discorre ser a cooperação algo iniciado antes da demanda e transcendente a um determinado processo. Em considerações anteriores, asseguramos que a mediação, finalmente, vinha recebendo seu merecido espaço em meio aos ideais de justiça reconstrutiva, em compasso com a visão de vanguarda do direito fraterno, bem como a relevância de se conferir atenção ao comportamento humano, por envolver desde aspectos como a boa-fé até a lealdade. Alinhados ao presente contexto, reafirmamos que a colaboração mútua, mesmo na mediação extrajudicial, segue com o suporte indireto do Estado na salvaguarda de princípios e

${ }^{21}$ MITIDIERO, Daniel. Processo justo, colaboração e ônus da prova. Revista do TST, Brasília, v. 78, n. 1, p. 67-77, jan./mar. $2012 . \quad$ Disponível em: https://juslaboris.tst.jus.br/bitstream/handle/20.500.12178/29621/003_mitidiero.pdf?sequence=4. Acesso em: 11 abr. 2021.

22 “o Estado Constitucional de modo nenhum pode ser confundido com o Estado-Inimigo". Idem.

23 “o processo cooperativo pressupõe o reconhecimento do caráter problemático do Direito, reabilitando-se a sua feição argumentativa. Passa-se da lógica apodítica à lógica dialética”. Ibidem.

24 "o processo pautado pela colaboração é um processo orientado pela busca, tanto quanto possível, da verdade" Ibidem.

25 “é a exceção que tem a pessoa para paralisar o comportamento de quem age dolosamente contra si”. Ibidem. 26 "revela a proibição de comportamento contraditório. Traduz o exercício de uma posição jurídica em contradição com o comportamento assumido anteriormente pelo exercente. Age contraditoriamente quem, dentro do mesmo processo, frustra a confiança de um de seus participantes". Ibidem.

27 “protege a boa-fé objetiva na medida em que proíbe a alegação de vícios formais por quem a eles deu causa, intencionalmente ou não, desde que por aí se possa surpreender aproveitamento indevido da situação criada com a desconstituição do ato". Ibidem.

28 “constitui a supressão de determinada posição jurídica de alguém que, não tendo sido exercida por certo espaço de tempo, crê-se firmemente por alguém que não mais passível de exercício”. Ibidem.

29 "A supressio leva a surrectio, isto é, ao surgimento de um direito pela ocorrência da supressio". Ibidem.

30 "traduz a proibição de determinada pessoa exercer posição jurídica oriunda de violação de norma jurídica por ela mesma patrocinada". Ibidem.

${ }^{31}$ WOLKART. Erik Navarro. Análise econômica do processo civil: como a Economia, o Direito e a Psicologia podem vencer a tragédia da justiça. São Paulo: Thomson Reuters Brasil, 2019, p. 93. 
garantias no seu atuar como instrumento regulador e fiscalizador ${ }^{32}$, razão pela qual manifestamos a importância de "transpassagem" da visão desse princípio no processo para assegurar a cooperação "transprocesso" como expectativa de comportamento positivo em jogos e negociações que conectem indivíduos em comunicação na busca por soluções, transformando-os de discordantes a transatores, assegurados por um sistema dotado de credibilidade global.

\section{Efetividade da consensualidade, fundamentações para a sanção pedagógica}

O Direito volta seu olhar para a conduta humana, construindo caminhos por meio de previsões normativas e sanções para a melhor proteção das relações sociais e para com o ambiente no qual os sujeitos estão inseridos. Conceitualmente, o Direito apresenta-se como um conjunto de regras e princípios que traçam garantias e punições de ordens pecuniárias quanto à liberdade, sendo a perda da liberdade a sanção de maior gravidade. Nos meandros das punições, as penas pecuniárias, ora de natureza coercitiva na ordem do dever moral e noutras como o próprio resultado punitivo do Estado-juiz, encontram no primeiro modelo a persuasão necessária ao cumprimento dos deveres morais e éticos daqueles envoltos em espaços de ADR.

Veja-se que as virtudes, na ótica de Aristóteles, são adquiridas pelo exercício "tal como acontece com as artes". A natureza humana tem capacidade de recebê-las, mas somente o hábito a aperfeiçoa. A virtude moral molda-se pelo hábito e não surge por natureza; nossas disposições morais nascem de atividades semelhantes a elas. E mais:

O que estamos dizendo é confirmado pelo que acontece nas cidadesEstados: os legisladores tornam bons os cidadãos por meio de hábitos que lhes incutem. Esse é o propósito de todos os legisladores, e quem não consegue alcançar tal meta, falha no desempenho de sua missão, e é exatamente neste ponto que reside a diferença entre a boa e má constituição.

Além disso, toda virtude é gerada e desconstruída pelas mesmas causas e pelos mesmos meios, do mesmo modo como acontece com toda arte:

\footnotetext{
${ }^{32}$ DUARTE, Márcia Michele Garcia Duarte, 2020, Op. cit.
} 
Revista Eletrônica de Direito Processual - REDP.

Rio de Janeiro. Ano 15. Volume 22. Número 3. Setembro a Dezembro de 2021

Periódico Quadrimestral da Pós-Graduação Stricto Sensu em Direito Processual da UERJ

Patrono: José Carlos Barbosa Moreira (in mem.). ISSN 1982-7636. pp. 684-709 www.redp.uerj.br

tocando a lira é que se formam os bons e os maus músicos. Isso se aplica igualmente aos arquitetos e a todos os demais; construindo o bem, tornamse bons arquitetos; construindo mal, maus. Com efeito, se assim não fosse não haveria necessidade de mestres, e todos os homens teriam nascidos bons e maus em suas profissões ${ }^{33}$ (grifos desse ensaio).

Para Maria Garcia ${ }^{34}$, até mesmo um grupo de bandidos pode ter sua regra moral. Leonardo Boff narra que essa prática se origina de costumes e integra a vida concreta; a prática real das pessoas, ressaltando que decorrem de hábito e valores culturalmente estabelecidos, podendo, inclusive serem questionados pela ética, na medida em que uma pessoa pode ser moral e não ser necessariamente ética ${ }^{35}$. Justificar o uso da sanção pecuniária como forma de impor condutas remonta o estudo da essência do Direito. Para Norberto Bobbio $^{36}$ :

Ao dizer que o direito é fundado, em última análise sobre o poder, e entendendo por poder o poder coercitivo, isto é, o poder de fazer respeitar, ainda que recorrendo à força, as normas editadas, não dizemos nada de diferente daquilo que afirmamos repetidamente em relação ao direito como conjunto de regras com eficácia reforçada. Se o direito é um conjunto de regras com eficácia reforçada, isto significa que um ordenamento jurídico é impensável sem o exercício da força, isto é, sem um poder. Pôr como fundamento último de um ordenamento jurídico positivo o poder não quer dizer reduzir o direito à força, mas simplesmente reconhecer que a força é necessária para a realização do direito. O que não é outra coisa senão acentuar o conceito de direito como ordenamento com eficácia reforçada (grifos desse ensaio).

\footnotetext{
${ }^{33}$ ARISTÓTELES. Ética a Nicômaco. Tradução: Pietro Nasseti. São Paulo: Martin Claret, 2006, p. 40-41.

34 GARCIA, Maria. Ética, Moral e Direito. YouTube. 1 vídeo $(9$ min). Disponível em: https://www.youtube.com/watch?v=NVdgp7XZ12w. Acesso em: 30 mar. 2021.

${ }^{35}$ BOFF, Leonardo. Ética e moral: a busca dos fundamentos. Op. Cit., p. 37.

${ }^{36}$ BOBBIO, Norberto. Teoria do Ordenamento Jurídico. Tradução: Ari Marcelo Solon. 2. ed. São Paulo: Edipro, 2014, p. 72-73.
} 
Afinados com esse pensamento, Atahualpa Fernandez e Marly Fernandez ${ }^{37}$ consideram o direito como "sendo um artefato cultural relacional, dinâmico e histórico, tem um caráter essencialmente instrumental e pragmático" "38. Ao analisar as questões atinentes à liberdade como pressuposto do atuar moral do homem, os autores delineiam que os homens criam para si, mediante hábitos e atos, uma segunda natureza denominada atividade moral como forma de atender à exigência de "sua própria e peculiar estrutura biopsicológica". Dado o fato de o homem ser constitutivamente um ser moral por razões bioestruturais e do construtivo sociocultural, desde os agrupamentos em coletividades primitivas ou préhistóricas e do nascimento da sua autoconsciência, o comportamento social passa a ser o produto das regras que regem a coletividade. Os autores narram também que somente se o homem for livre, poderá ser moralmente responsável pelos seus atos, destacando que o alcance do nosso controle volitivo é o alcance de nossa liberdade ${ }^{39}$.

Essa abordagem mostra-se deveras oportuna, quando comparada ao momento histórico contemporâneo marcado pela transição do referencial de monopólio do Estado na tutela jurisdicional, após a necessária limitação à autotutela primitiva, rumo à autonomia dos indivíduos na resolução dos próprios conflitos e construindo escritos válidos e vinculativos, a ponto de se habilitarem como títulos executivos extrajudiciais. Noutras vezes, delega-se ao sistema paraestatal da arbitragem, que sequer está sob a fiscalização do Conselho Nacional de Justiça, a solução das disputas na forma de heterotutela, num espaço sem necessária participação julgadora de bacharel em Direito. Podem, ainda, no âmbito dos juizados especiais, sem advogados, particulares que desconhecem o direito enquanto formação transacionar na presença de conciliadores muitas vezes sem formação acadêmica concluída. Sujeita-se à homologação o que for acordado, porém nem sempre a figura de um jurista comporá a mesa de negociação, conferindo extrema autonomia aos jurisdicionados naquele momento.

Se a moral decorre de uma construção de grupos e o direito serve a induzir caminhos de moralidade através de modelos coercivos e sancionatórios, revela-se condizente, razoável e moldado sob os estreitos limites dos princípios da cooperação, da colaboração e da boa-fé,

\footnotetext{
${ }^{37}$ FERNANDEZ, Atahualpa; FERNANDEZ, Marly. Neuroética, Direito e Neurociência. Curitiba: Juruá, 2008.

${ }^{38}$ Idem, p. 59.

${ }^{39}$ Ibidem, p. 78-79.
} 
que condutas inadequadas, sorrateiras e antiéticas no discurso da negociação sejam penalizadas como forma de construir novo arcabouço de percepção do justo.

Provoca-se isso na medida em que vícios como o blefe e outras condutas do negociador podem fugir aos aspectos dos deveres kantianos ${ }^{40}$ que revelam imperativos para a convivência harmoniosa e respeitosa entre os indivíduos. Naquela senda, o espaço da negociação pode se tornar um caminho de manipulação dos oponentes, criação de expectativas e traições negociais. Nada se refere aqui ao eventual descumprimento da obrigação entabulada pelos transatores. Diz-se do período negocial em si quanto à "distração" e sedução do opositor com promessas que não passam de palavras ao vento com o objetivo de traquinagem e franco desrespeito humano ao que ocupa o outro lado da mesa.

Pois bem: é necessário romper com esse ciclo vicioso da busca por vantagens e sobreposição de forças para que se possa atingir a construção de nova ordem moral e isso exige, prementemente, a tomada de medidas coercitivas e coibidoras de conduta nociva aos deveres de lealdade, o que se faz por meio da norma de sanção.

\section{Aumentando a envergadura de estímulos (coercitivos) à busca prévia pela resolução consensual}

Numa senda negocial direta ou viabilizada pela via heterocompositiva, alguns comportamentos que não devem ser realizados podem se mostrar na contramão do propósito de pacificar, enfraquecendo o instrumento e fragilizando todas as técnicas disponíveis para a real e adequada resolução amigável dos conflitos, incluindo as vias desjudicializadas.

Para Humberto Dalla, a desjudicialização mostra-se um verdadeiro fenômeno enquanto ferramenta de racionalização da prestação jurisdicional e ajuste ao cenário contemporâneo. Propõe o autor a necessária releitura e atualização e, ainda, o que denominada de "redimensionamento da garantia constitucional do acesso à justiça, à luz dos

\footnotetext{
${ }^{40}$ Imperativo categórico de Kant: "Age só segundo a máxima tal que possas ao mesmo tempo querer que ela se torne lei universal". Discorre ainda: "Age de tal maneira que possas usar a humanidade, tanto em tua pessoa como na pessoa de qualquer outro, sempre e simultaneamente com o fim e nunca simplesmente como meio. (...) Mas é melhor, no juízo moral, proceder sempre pelo imperativo categórico: 'age segundo a máxima que possa simultaneamente fazer a si mesma lei universal"'. (grifos desse ensaio). KANT, Immanuel. Fundamentação da Metafísica dos Costumes e Outros Escritos. São Paulo: Martin Claret, 2005, p. 51-67.
} 


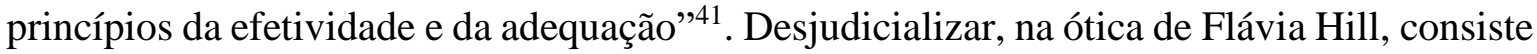
igualmente num fenômeno. Os litígios ou atos da vida civil não ficam mais exclusivamente na dependência da intervenção judicial para ser dada a solução válida, na medida em que esse resultado pode ser alcançado perante agentes externos ao Poder Judiciário, num contexto que a autora explica ser "consecução do acesso à justiça fora do Poder Judiciário, ou seja, do acesso à justiça extramuros". 42

Consideramos, em estudo anterior, ser um grande passo reconhecer a importância da desjudicialização como forma de viabilizar maior celeridade dos feitos e conferir aos envolvidos a participação ativa na construção do resultado oficial. Defendemos maior satisfatividade e finalização da contenda de forma efetiva e eficaz, servindo a desjudicialização como ferramenta promissora na solução de pendências jurídicas a auxiliar no processo de desobstrução na pletora de demandas da Casa Judiciária ${ }^{43}$.

Diante de notórios incentivos à busca pela forma alternativa à via adjudicatória, vistos os elementos necessários à boa condução no modelo multiportas, percebeu-se também aquilo que deve estar afastado para a efetividade desse sistema consensual que, por sua vez, ocorre em momentos pré-processuais ou mesmo extraprocessuais. Conferir a segurança e o dever de conduta imbuído de boa-fé quando da prática dos atos processuais está expresso no Código de Processo. Mas, e quando se tratar de mero procedimento nas hipóteses em que a questão ainda não se encontra instrumentalizada na acepção técnica do termo?

Hipoteticamente, vale considerar que pessoas em adversidade de vizinhança estejam buscando solucionar a questão com orientação jurídica de seus advogados. Alinhados, após reuniões para discutirem os seus interesses, uma das partes propõe a elaboração da minuta do Termo de Transação (algo extremamente comum na rotina das mediações quando o termo de composição deva ser integrado por número considerável de elementos). No momento seguinte, o documento é compartilhado entre todos os envolvidos (interessados e demais

\footnotetext{
41 PINHO, Humberto Dalla Bernardina de. A releitura do princípio do acesso à justiça e o necessário redimensionamento da intervenção judicial na resolução dos conflitos na contemporaneidade. Revista EMERJ, Rio de Janeiro, v. 21, n. 3, t. 1, p. 241-271, set./dez. 2019. Disponível em: https://www.emerj.tjrj.jus.br/ revistaemerj_online/edicoes/revista_v21_n3/tomo1/revista_v21_n3_tomo1_241.pdf. Acesso em: 24 mar. 2021.

${ }^{42}$ HILL, Flávia Pereira. Desjudicialização e acesso à justiça além dos tribunais: pela concepção de um devido processo legal extrajudicial. Revista Eletrônica de Direito Processual (REDP), Rio de Janeiro, ano 15, v. 22, n. 1, jan./abr. 2021. Disponível em: https://www.epublicacoes.uerj.br/index.php/redp/article/view/56701/36324. Acesso em: 6 abr. 2021.
}

43 DUARTE, Márcia Michele Garcia Duarte, 2020, Op. Cit. 
advogados), sendo feitas algumas ponderações pelo outro transator e devolvido o documento ao redator. Como resposta, em vez de realizarem em conjunto os ajustes finais no entabulado, a parte oponente é meramente comunicada pela redatora acerca do ajuizamento da ação, sendo surpreendida no curso do que seria uma negociação e se transmutou em frustração e sensação de ter sido ludibriada.

Pois bem: a despeito de o livre e regular exercício do direito de ação ser uma garantia constitucional ( $5^{\circ}, \mathrm{XXXV}$, da $\left.\mathrm{CRFB} / 88\right)$, do ponto de vista da ética nas negociações, fulminou-se nesse caso a relação de confiança que consagra o elemento da transparência. Além de surpreender o oponente com a colocação da questão em litigiosidade judicial (real figuração da "corrida do ouro"), impõe ao outro, que se mostrava disponível à consensualidade, emaranhar-se na teia de riscos processuais e sucumbenciais, aumento de seus custos de maneira coercitiva, com a eliminação de qualquer possibilidade de comunicação futura no curso do processo, mesmo que se tente a via endoprocessual de resolução por consensualidade.

Outra clara hipótese de surpresa negativa decorre do simples abandono tácito "da mesa" por um dos negociadores sem o encerramento expresso das tratativas, deixando a outra parte "no aguardo" e mesmo em "em banho-maria". Move-se o retirante lentamente sem conferir ao oponente a real dimensão dos acontecimentos e do desinteresse em seguir na negociação. Na outra ponta e na expectativa de receber nova proposta ou contraproposta, uma das partes segue esperançosa diante da promessa subjetiva criada naquele jogo, ao passo que o outro negociador trata a questão sem qualquer preferência ou deferência, e também não expressa o encerramento, levando ao arrastamento da situação até o outro se mostrar cansado, desista e abandone sua pretensão, ou mesmo aceite, dada a exaustão, acordos anteriormente inaceitáveis.

Seguramente, elementos caros ao direito processual como a prescrição estão a salvo por força do disposto no artigo 202, VI, do Código Civil, se comprovado o ato inequívoco que importe em reconhecimento do direito do devedor, ainda que se realize no campo extrajudicial ${ }^{44}$. Entretanto, o desgaste, a frustração e a sensação de banalização refutam a

\footnotetext{
${ }^{44}$ Considere a situação na qual se instalaram as de tratativas para a autocomposição e um dos indivíduos em conflito manifeste vinculação à obrigação para pagamento de quantia determinada, requerendo prazo para apresentar contraproposta quanto à forma de pagamento no que tange a parcelamentos e prazos. Essa manifestação inequívoca perante o credor e terceiros (advogados dos transatores, por exemplo), interrompe o
} 
construção e a introjeção na rotina social da busca pela solução pacificada e autocompositiva dos conflitos.

Os indivíduos são estimulados a buscar métodos consensuais de solução de conflitos e são tocados, indubitavelmente, pelo princípio do empoderamento ${ }^{45}$. Ao se mostrarem abertos à matriz consensualista, devem estar a salvo de qualquer tipo de risco que não suportariam se tivessem optado, prima facie, pelo sistema tradicional de prestação jurisdicional polarizada. Isso compõe os deveres morais a serem erigidos, nas feições aqui assinaladas, por meio da força coercitiva do direito na construção de condutas e valores almejados para a preservação da liberdade coletiva.

$\mathrm{O}$ CPC confere força principiológica à boa-fé processual, associada aos deveres de cooperação e de colaboração e merece estímulo para serem reservadas também às condutas extrajudiciais. Dos ensinamentos de Daniel Mitidiero, extrai-se que a colaboração, enquanto modelo erguido a partir de pressupostos culturais, deve ser provido sob ordem governamental. Para o doutrinador, o "Estado deixa de ter um papel de pura abstenção e passa a ter que prestar positivamente para cumprir com seus deveres constitucionais". ${ }^{46}$

Assentados sobre essa máxima, defendemos que o Estado deve se mostrar ativo e instituir medidas para blindar os indivíduos abertos à consensualidade da mácula da má-fé. A boa-fé se realiza por meio do princípio da moralidade e transcende o direito privado, ao passo que situações jurídicas das mais variadas impõem o comportamento correto, honesto, equânime, proporcional, expectando-se por comportamentos éticos e transparentes que inspirem confiança, conforme lições de Rogério Donnini ${ }^{47}$.

Movimentos legislativos ensaiam a aplicação de penalidades aos negociadores que se comportam de maneira contrária à boa-fé. A título de exemplo, aponta-se a proposta de

curso do prazo prescricional, por se tratar de manifestação fora de dúvida que se revela no próprio ato. Nesse caso, o direito de interromper do prescribente é verificado diante do evidente reconhecimento à legitimidade da dívida sem qualquer esforço hermenêutico necessário à compreensão de assunção do dever obrigacional.

${ }^{45}$ Conselho Nacional de Justiça. Código de Ética de Conciliadores e Mediadores Judiciais (Anexo III à Resolução n ${ }^{\circ} 125$, de 29 de novembro de 2010). "Art. $1^{\circ}$ São princípios fundamentais que regem a atuação de conciliadores e mediadores judiciais: confidencialidade, decisão informada, competência, imparcialidade, independência e autonomia, respeito à ordem pública e às leis vigentes, empoderamento e validação. [...]. VII - Empoderamento - dever de estimular os interessados a aprenderem a melhor resolverem seus conflitos futuros em função da experiência de justiça vivenciada na autocomposição." Disponível em: https://www.cnj.jus.br/wp-content/uploads/2014/04/resolucao_125_29112010_23042014190818.pdf. Acesso em: 14 abr. 2021 (grifo desse ensaio).

${ }^{46}$ MITIDIERO, Daniel, Op. Cit.

${ }^{47}$ DONNINI, Rogério José Ferraz. Bona Fides: do Direito Material ao Processual. Revista de Processo, São Paulo, v. 251, p. 113-126, jan. 2016. 
Medida Provisória da Senadora Soraya Thronicke ${ }^{48}$ que sugere acrescer, entre outros, ao Código de Processo Civil o art. 17-A e ainda o § 13-A ao art. 85, com o escopo de atuar em resposta ao comportamento do réu na fase antecedente ao espaço processual. A justificativa legislativa discorre sobre a necessária punição de parte que tiver "recusado acordo vantajoso" e quando "o Judiciário - ao fim e ao cabo - decidir pelo deferimento de indenização menor do que a proposta formalmente por uma das partes”. Sinaliza que a proposta decorre diretamente de estudo realizado entre o Conselho Nacional de Justiça (CNJ) e a Pontifícia Universidade Católica do Rio Grande do Sul (PUC-RS), com o objetivo de remediar a excessiva judicialização brasileira. No que tange ao texto do Projeto, veja-se o seguinte:

Art. 17-A. Quando os litígios versarem sobre direitos patrimoniais disponíveis, o interesse processual somente estará presente com a prévia constituição de controvérsia jurídica entre as partes.

$\S 1^{\circ}$ Considera-se constituída a controvérsia jurídica entre as partes com a notificação do requerido pelo requerente, previamente ao ajuizamento da ação.

$\S 2^{\circ}$ A notificação extrajudicial, a que se refere o $\S 1^{\circ}$, deverá:

I - estabelecer a mora jurídica que fundamente o interesse jurídico da ação; $\mathrm{e}$

II - oferecer prazo para autocomposição ou acordo extrajudicial entre as partes.

$\S 3^{\circ}$ A notificação deverá ser encaminhada, pelo advogado ou defensor público constituído pelo autor, ao endereço eletrônico da parte ré que tenha sido:

I - cadastrado no sistema a que se refere o art. 246, quando a parte ré for pessoa jurídica; ou

II - estabelecido como meio de comunicação entre as partes, quando a parte ré for pessoa natural.

$\S 4^{\circ} \mathrm{O}$ interesse processual constituído é válido somente:

\footnotetext{
${ }^{48}$ BRASIL. Senado Federal. Proposta de Emenda à Medida Provisória no 1.040, de 2021. Brasília, DF: Senado Federal. 2021. Disponível em: https://legis.senado.leg.br/sdleggetter/documento?dm=8948576\&disposition=inline. Acesso em: 14 abr. 2021.
} 
I - após o prazo estabelecido na forma do inciso II do $\S 2^{\circ}$; e

II - trinta dias após o último ato decorrente da notificação entre as partes.

$\S 5^{\circ}$ Quando, em razão das circunstâncias de fato e de direito, for imprescindível a antecipação de tutela do pleito do autor, a notificação extrajudicial será enviada concomitantemente ao ajuizamento do pedido de antecipação de tutela, ficando o prosseguimento da ação condicionado ao cumprimento do disposto nos $\S \S 1^{\circ} \mathrm{e} 2^{\circ}$.

$\S 6^{\circ}$ Fica dispensada a necessidade de constituir controvérsia jurídica na ausência de disponibilidade de endereço eletrônico na forma do $\S 3^{\circ}$. (NR)

Art.85.

(..)

$\S 13-A$. A parte que negar uma oferta formal de acordo, em uma disputa de direito patrimonial disponível, e posteriormente obtiver em juízo um valor de condenação inferior à proposta anteriormente formalizada pela parte contrária, será condenada ao ônus sucumbencial pelo uso desnecessário do sistema público de solução de controvérsias.

Ainda no âmbito da agenda legislativa, tem-se o Projeto de Lei n ${ }^{\circ} 533 / 2019^{49}$, de autoria do Deputado Júlio Delgado e relatoria do Deputado Vinícius Carvalho ${ }^{50}$ pela aprovação do PL e da emenda $\mathrm{n}^{\circ}$ 1/2019, "apresentada ao substitutivo, com substitutivo"51. Justificou-se na afirmativa de que o réu deverá ser penalizado pelo juiz se não propiciar

\footnotetext{
${ }^{49}$ BRASIL. Câmara dos Deputados. Projeto de Lei no 533 , de 06 de fevereiro de 2019. Acrescenta o parágrafo único ao artigo 17 e $\S 3^{\circ}$ ao artigo 491, ambos do Código de Processo Civil. Brasília, DF: Câmara dos Deputados, 2019.2 Disponível em: https://www.camara.leg.br/proposicoesWeb/fichadetramitacao?idProposicao=2191394. Acesso em: 14 abr. 2021.

${ }^{50}$ BRASIL. Câmara dos Deputados. Substitutivo $\mathrm{n}^{\circ} 1$ CDC ao Projeto de Lei $\mathrm{n}^{\circ}$ 533, de 06 de fevereiro de 2019. Acrescenta os $\S \S 1^{\circ}$ e $2^{\circ}$ ao artigo 17 e $\S 3^{\circ}$ ao artigo 491, do Código de Processo Civil. Brasília, DF: Câmara dos Deputados, 2019. Disponível em: https://www.camara.leg.br/proposicoesWeb/fichadetramitacao?idProposicao=2206685. Acesso em $14 \mathrm{abr}$. 2021.

${ }^{51} \mathrm{O} P L{ }^{\circ}{ }^{\circ}$ 533/2019 foi apresentado ao Plenário em 06/02/0219, seguindo para a Mesa Diretora em 19/03/2021, donde foi exarado o despacho: "Às Comissões de Defesa do Consumidor e Constituição e Justiça e de Cidadania (Mérito e Art. 54, RICD) - Art. 24, II Proposição Sujeita à Apreciação Conclusiva pelas Comissões - Art. 24 II Regime de Tramitação: Ordinária (Art. 151, III, RICD”. O PL foi remetido à Comissão de Defesa do Consumidor em 20/03/2019, onde permanecia na data de fechamento deste trabalho.
} 
solução extrajudicial e amigável quando procurado pelo autor e, com isso, aquele ter dado causa ao ajuizamento da questão. Propõe a seguinte redação ao Código de Processo Civil:

Art. 17.

\section{(...)}

$\S 1^{\circ}$ Em caso de direitos patrimoniais disponíveis, para haver interesse processual é necessário ficar evidenciada a resistência do réu em satisfazer a pretensão do autor. (NR)

$\S 2^{\circ}$ Tratando-se de ação decorrente de relação de consumo, a resistência mencionada no $\S 1^{\circ}$ será demonstrada pela comprovação da tentativa extrajudicial de satisfação da pretensão do autor diretamente com o réu, ou junto aos órgãos integrantes da Administração Pública ou do Sistema Nacional de Defesa do Consumidor. (NR) (parágrafo pelo substitutivo anexo ao relatório).

Art. 491

(...)

$\S 3^{\circ} \mathrm{Na}$ definição da extensão da obrigação, o juiz levará em consideração a efetiva resistência do réu em satisfazer a pretensão do autor, inclusive, no caso de direitos patrimoniais disponíveis, se o autor, por qualquer meio, buscou a conciliação antes de iniciar o processo judicial. (NR)

Diante dessas postulações, propomos a aplicação dos princípios ventilados neste ensaio também na fase pré-processual e nos casos extraprocessuais. Naturalmente, a sanção deve ser aplicada pela via própria, porém, deve-se resguardar que se torne tangível a punição daqueles que atuam violando os deveres da ética negocial, seja no abandono da negociação ou na desistência infundada da via extrajudicial e mesmo pré-processual.

Para conferir maiores garantias ao acordo, ousamos propor, de lege ferenda, que se considere a possibilidade de registro dos elementos integrantes do Termo de Transação Civil (identificação das partes e obrigação pactuada) de modo equivalente ao que se dá pela via da averbação premonitória disposta no art. 828 do CPC, ainda que não tenha havido inadimplência e a questão não esteja em juízo. 


\section{É necessário desbravar caminhos com vistas a conferir maiores garantias àquele} que se dispõe a confiar num sistema sem rotulação do modelo adjudicatório. Ademais, o mero ajuizamento da ação cognitiva habilitaria a expedição de certidões de registro das distribuições judiciais com o escopo de gerar garantias e publicizar os riscos negociais, posto que servem, ao fim e ao cabo, para informar bens cuja titularidade possa ser ameaçada. Como resultante dessa correlação, apontamos sólido fundamento a justificar que possam ser feitas averbações acautelatórias também tendo como instrumento o título executivo extrajudicial formado a partir de acordos celebrados através do uso da mediação ou mediante negociações diretas, ainda que tal escrito não tenha sido homologado e nem sequer inadimplido.

Neste recorte, confere-se especial destaque à proteção e aos efeitos decorrentes das hipóteses elencadas no art. 792 do CPC que se mostram mais graves ao devedor que objetiva se furtar da obrigação por meio da alienação ou oneração de bens. Da leitura dos incisos I a IV, extrai-se apenas a aplicação dessa garantia às questões judicializadas. O inciso $\mathrm{V}$, entretanto, possibilita a complementação capaz de abarcar (considerando nossa proposta de lege ferenda) questões que tenham sido objeto de Transação Civil Extrajudicial, uma vez que através do correspondente Termo, extrai-se a assunção da obrigação. Busca-se conferir, por meio dessa ampliação, maiores e mais seguras garantias de cunho preventivo e acautelatório em favor do credor. Além disso, por meio do ato registral declaratório, independentemente de anuência do devedor, viabilizam-se todos os desdobramentos da averbação premonitória, como a publicidade para conhecimento por terceiros (ampliando a relação linear entre credor e devedor, gerando efeitos oponíveis erga omnes), a individuação do bem, questionamento quanto a fraudes e o privilégio em eventual execução que alcance a fase de expropriação de bens.

Ao conferir essas ferramentas protetivas dos interesses do credor, atende-se aos fins sociais do propósito desjudicializador e revela garantia que transcende o mero fomento àqueles dotados de pretensão que estão sendo incentivados a seguirem pelo caminho consensualista. Em complemento, serve de estímulo moral no desiderato abordado neste estudo, levando aquele que originalmente figuraria no polo passivo de uma demanda litigiosa ao espaço da benesse de negociar, em vez de ser demandado.

\section{Considerações finais}


Em epílogo, considera-se que este ensaio trouxe importante alerta para questões pragmáticas, cujo enfrentamento incipiente poderá contribuir para a melhora nos resultados e na recepção cultural do sistema multiportas. Observando-se também os pontos destacados no decorrer deste trabalho, entendemos que se conferirão segurança e efetividade ao sistema que concede autonomia e protagonismo aos indivíduos na busca pelo efeito "ganha-ganha", devendo encontrar meios para que assim seja realmente percebido.

Disciplinar a arbitragem, divulgar os meios para negociação direta, abrir espaços para mediação e conciliação, incentivar seu uso e instruir os operadores do direito e a sociedade, tem sido uma política louvável e digna de muitos aplausos. Para se atingir o resultado almejado, entretanto, não basta abrir as portas e prestar esclarecimentos. É preciso conferir garantias aos transatores e, especialmente, àqueles que abdicam do caminho tradicional adjudicatório e seguro para experimentar um caminho alternativo, portando a rubrica de ser amigável, amistoso e adequado para aquele tipo de conflito.

Se o que se pretende é reduzir disputas e extrair do conflito apenas seu lado benéfico de crescimento e evolução social, nesse mesmo compasso deve estar presente a segurança esperada de qualquer medida de proteção lato sensu, pois na tutela jurisdicional tradicional os elementos transparência e proteção são garantias, devendo a confiança ser também garantia no acesso à justiça pela via alternativa.

Essa confiança, como visto, decorre do caráter e da disposição moral que se constrói através de costumes e hábitos. No momento atual brasileiro, que consagra período de transição e aceitação do novo, ainda há de se realizar a reeducação social no sentido de impregnar o comportamento ético e respeitoso do ponto de vista universalizante; há de se construírem modelos e valores, exigindo proatividade do Estado na função normativa sancionadora de comportamentos inadequados.

A boa-fé, por vezes alinhada a outros princípios como o da cooperação, embasa atos judiciais punitivos autorizados pela norma processual, como se observa em diversas passagens de aplicação de reprimenda ao comportamento atentatório à dignidade da justiça.

Sob esta mesma justa causa social, a sanção civil de cunho pedagógico deve ser aplicada a atos praticados em procedimento fora do espaço judiciário (meios extrajudiciais) e/ou antecedente ao processo (via pré-processual, como se dá nos Centros Judiciários de 
Solução de Conflitos e Cidadania - CEJUSC's), a fim de coibir posturas desleais e "antidesportivas" entre aqueles que se encontram em jogos negociais e ferem a ética das negociações. O mesmo deve ser aplicado àqueles que abandonam tacitamente a mesa negocial ou desistem da resolução consensualizada de maneira infundada, retardando a solução do conflito e provocando o Judiciário, para se atingir, ao final, a mesma linha de chegada que se alcançaria pela via alternativa mais célere, além de impor ao oponente os custos, encargos e riscos do processo.

Caso os payoffs considerem os riscos e consequências de jogarem com ferramentas lícitas, porém, dotadas de finalidade moralmente reprovável, cientes do risco de punição pecuniária por protelar aquilo que se atingiria pela via consensualizada, os negociadores ponderarão com mais empenho e esmero as oportunidades emergidas na senda das matrizes alternativas. Em complemento, quem possui pretensão legítima e com grandes chances de êxito na vereda processual, ainda que o elemento "ganha" atingido ao final da transação não represente a totalidade originalmente almejada, diante do que poderia alcançar pela via judiciária, optará, firme em maior segurança, pelo caminho alternativo.

Nesse tipo de escolha, ganha-se pelo social. Por isso, devem ser depuradas as toxicidades imbuídas nos indivíduos pela vida moderna regada a consumismo, acumulações inúteis e vazio existencial que fomentam dissabores, fúria, egoísmo, conflitos, crises e disputas. Deve-se, ainda que pela via sancionadora pecuniária (e pedagógica), impor condutas, reconstruir valores de respeito ao próximo enquanto simplesmente postura ética, e ao adversário no aspecto de dignidade da pessoa humana. Deve-se, ainda, nutrir a visão altruísta, coletiva e amistosa, elementos invocados em diversos escritos da visão moderna que pregam o direito mais acolhedor, fraterno e humanizado, e que tanto podem contribuir para a verdadeira efetividade do promissor e louvável sistema multiportas.

\section{REFERÊNCIAS}

ARISTÓTELES. Ética a Nicômaco. Tradução: Pietro Nasseti. São Paulo: Martin Claret, 2006.

BOBBIO, Norberto. Teoria do Ordenamento Jurídico. Tradução: Ari Marcelo Solon. 2. ed. São Paulo: Edipro, 2014. 
BOFF, Leonardo. Ética e moral: a busca dos fundamentos. 2. ed. Petrópolis, RJ: Vozes, 2004.

BOFF, Rubem José. Negociação: técnicas para a obtenção de resultados. Interlink, Aparecida de Goiânia, v. 2, n. 2, jul./dez. 2011. Disponível em: https://www.fd.unl.pt/docentes_docs/ma/tgau_MA_26100.pdf. Acesso em: 29 mar. 2021.

BRASIL. Câmara dos Deputados. Projeto de Lei nº 533, de 06 de fevereiro de 2019. Acrescenta o parágrafo único ao artigo 17 e $\S 3^{\circ}$ ao artigo 491, ambos do Código de Processo Civil. Brasília, DF: Câmara dos Deputados, 2019. Disponível em: https://www.camara.leg.br/proposicoesWeb/fichadetramitacao?idProposicao=219139 4. Acesso em: 14 abr. 2021.

BRASIL. Câmara dos Deputados. Substitutivo no 1 CDC ao Projeto de Lei no 533, de 06 de fevereiro de 2019. Acrescenta os $\S \S 1^{\circ}$ e $2^{\circ}$ ao artigo 17 e $\S 3^{\circ}$ ao artigo 491 , do Código de Processo Civil. Brasília, DF: Câmara dos Deputados, 2019. Disponível em: https://www.camara.leg.br/proposicoesWeb/fichadetramitacao?idProposicao=220668 5. Acesso em 14 abr. 2021.

BRASIL. Conselho Nacional de Justiça. Resolução no 125 , de 29 de novembro de 2010. Dispõe sobre a Política Judiciária Nacional de tratamento adequado dos conflitos de interesses no âmbito do Poder Judiciário e dá outras providências. Disponível em: https://www.cnj.jus.br/wp-content/uploads/2014/04/resolucao_125_29112010_ 23042014190818.pdf. Acesso em: 18 abr. 2021.

BRASIL. Ministério da Educação. Resolução n 5, de 17 de dezembro de 2018. Institui as Diretrizes Nacionais do Curso de Graduação em Direito e dá outras providências. Disponível em: https://www.in.gov.br/materia//asset_publisher/Kujrw0TZC2Mb/content/id/ 55640393/do1-2018-12-18-resolucaon-5-de-17-de-dezembro-de-2018-55640113. Acesso em: 17 abr. 2021.

BRASIL. Presidência da República. Lei n 13.105, de 16 de março de 2015. Código de Processo Civil. Disponível em: http://www.planalto.gov.br/ccivil_03/_ato20152018/2015/lei/113105.htm. Acesso em: 9 jun. 2020.

BRASIL. Presidência da República. Lei n 13.140, de 26 de junho de 2015. Dispõe sobre a mediação entre particulares como meio de solução de controvérsias e sobre a 
autocomposição de conflitos no âmbito da administração pública; altera a Lei n ${ }^{\circ} 9.469$, de 10 de julho de 1997, e o Decreto $n^{\circ} 70.235$, de 6 de março de 1972; e revoga o $\S 2^{\circ}$ do art. $6^{\circ}$ da Lei $\mathrm{n}^{\circ}$ 9.469, de 10 de julho de 1997. Disponível em: http://www.planalto.gov.br/ccivil_03/_Ato2015-2018/2015/Lei/L13140.htm. Acesso em: 15 jun. 2020.

BRASIL. Senado Federal. Proposta de Emenda à Medida Provisória no 1.040, de 2021. Brasília, DF: Senado Federal. 2021. Disponível em: https://legis.senado.leg.br/sdleggetter/documento?dm=8948576\&disposition=inline. Acesso em: 14 abr. 2021 .

CONSUMIDOR.GOV.BR. Conteúdo sobre serviço. Disponível em: https://www.consumidor.gov.br/pages/conteudo/sobre-servico. Acesso em: 13 abr. 2021.

CUNHA, Leonardo Carneiro da. Justiça multiportas: mediação, conciliação e arbitragem no Brasil. Revista ANNEP de Direito Processual, Salvador-BA, v. 1, n. 1, art. 33, 2020, p. $140-162$. Disponível em: https://revistaannep.com.br/index.php/radp/article/view/33/pdf. Acesso em: 2 mar. 2021.

DONNINI, Rogério José Ferraz. Bona Fides: do Direito Material ao Processual. Revista de Processo, São Paulo, v. 251, p. 113-126, jan. 2016.

DUARTE, Márcia Michele Garcia. Argumentação participativa - o encontro com a virtuosidade humana: motivos para o êxito da justiça restaurativa no combate e prevenção da violência doméstica. Curitiba: CRV, 2016.

DUARTE, Márcia Michele Garcia Duarte. O papel social do advogado no primado da mediação e a argumentação participativa. In: PINTO, Adriano Moura da Fonseca Humberto; PINHO, Dalla Bernardina; DUARTE, Márcia Michele Garcia; MARTÍN, Nuria Belloso (Coord.). Estudos sobre mediação: no Brasil e no exterior. Essere nel Mondo, Santa Cruz do Sul, v. 1, p. 194-211, 2020. Disponível em: https://www.esserenelmondo.com/pt/direito-estudos-sobre-mediacao-no-brasil-e-noexterior-ebook193.php. Acesso em 14 abr. 2021.

FERNANDEZ, Atahualpa; FERNANDEZ, Marly. Neuroética, Direito e Neurociência. Curitiba: Juruá, 2008. 
GARCIA, Maria. Ética, Moral e Direito. YouTube. 1 vídeo (9 min). Disponível em: https://www.youtube.com/watch?v=NVdgp7XZ12w. Acesso em: 30 mar. 2021.

HILL, Flávia Pereira. Desjudicialização e acesso à justiça além dos tribunais: pela concepção de um devido processo legal extrajudicial. Revista Eletrônica de Direito Processual (REDP), Rio de Janeiro, ano 15, v. 22, n. 1, jan./abr. 2021. Disponível em: https://www.e-publicacoes.uerj.br/index.php/redp/article/view/56701/36324. Acesso em: 6 abr. 2021.

KANT, Immanuel. Fundamentação da Metafísica dos Costumes e Outros Escritos. São Paulo: Martin Claret, 2005.

MAZZOLA, Marcelo Leite da Silva. Tutela jurisdicional colaborativa: a cooperação como fundamento autônomo de impugnação. Curitiba: CRV, 2017.

MITIDIERO, Daniel. Processo justo, colaboração e ônus da prova. Revista do TST, Brasília, v. 78, n. 1, p. 67-77, jan./mar. 2012. Disponível em: https://juslaboris.tst.jus.br/bitstream/ handle/ 20.500.12178/29621/003_mitidiero.pdf?sequence=4. Acesso em: 11 abr. 2021.

MOREIRA, José Carlos Barbosa. Temas de Direito Processual. Oitava Série. São Paulo: Saraiva, 2004.

PINHO, Humberto Dalla Bernardina de. A cooperação como elemento estruturante da interface entre o Poder Judiciário e o Juízo Arbitral. Revista Eletrônica de Direito Processual (REDP), Rio de Janeiro, ano 11, v. 18, n. 3, p. 198-218, set./dez. 2017.

PINHO, Humberto Dalla Bernardina de. A releitura do princípio do acesso à justiça e o necessário redimensionamento da intervenção judicial na resolução dos conflitos na contemporaneidade. Revista EMERJ, Rio de Janeiro, v. 21, n. 3, t. 1, p. 241-271, set./dez. 2019. Disponível

em: https://www.emerj.tjrj.jus.br/revistaemerj_online/edicoes/revista_ v21_n3/tomo1/revista_v21_n3_tomo1_241.pdf. Acesso em: 24 mar. 2021.

PINHO, Humberto Dalla Bernardina de; MAZZOLA, Marcelo. Manual de Mediação e Arbitragem. São Paulo: Saraiva Educação, 2019.

URY, William; FISHER, Roger; PATTON, Bruce. Como chegar ao sim: como negociar acordos sem fazer concessões. Tradução: Rachel Agavino. Rio de Janeiro: Sextante, 2018 
Revista Eletrônica de Direito Processual - REDP.

Rio de Janeiro. Ano 15. Volume 22. Número 3. Setembro a Dezembro de 2021

Periódico Quadrimestral da Pós-Graduação Stricto Sensu em Direito Processual da UERJ

Patrono: José Carlos Barbosa Moreira (in mem.). ISSN 1982-7636. pp. 684-709 www.redp.uerj.br

WOLKART. Erik Navarro. Análise econômica do processo civil: como a Economia, o

Direito e a Psicologia podem vencer a tragédia da justiça. São Paulo: Thomson Reuters

Brasil, 2019. 